\title{
Overcoming Zn Segregation in CdZnTe with the Temperature Gradient Annealing
}

\author{
K. Kim, ${ }^{\mathrm{a}, *}$ A. E. Bolotnikov ${ }^{\mathrm{b}}$, G. S. Camarda ${ }^{\mathrm{b}}$, A. Hossain ${ }^{\mathrm{b}}$, R. B. James ${ }^{\mathrm{b}}$ \\ ${ }^{a}$ Department of Radiologic Science, Korea University, Seoul 136-713, Republic of Korea \\ ${ }^{b}$ Brookhaven National Laboratory, Upton, NY 11973 USA
}

\begin{abstract}
The availability of large volume crystals with the same energy gap in melt-grown $\mathrm{CdZnTe}(\mathrm{CZT})$ is restricted due to the Zn segregation in CdTe hosts. We observed the migration of $\mathrm{Zn}$ in the solid phase along the positive temperature gradient direction both in-situ and post-growth temperature gradient annealing (TGA) of CZT. Diffusivity of $\mathrm{Zn}$ obtained from the in-situ TGA was approximately $10^{-5}$ $\left(\mathrm{cm}^{2} / \mathrm{s}\right)$ order and completely different mechanism with that of post-growth. The CZT ingots obtained through in-situ TGA have uniform Zn and resistivity of $10^{10} \Omega \cdot \mathrm{cm}$ orders. The CZT detectors fabricated from in-situ TGA applied ingots exhibit $10 \%$ of energy resolution for $59.5 \mathrm{keV}$ peak of ${ }^{241} \mathrm{Am}$.

Keywords: A1. Segregation, A2. Bridgman technique, B1. Cadmium compounds, B2. Semiconducting II-VI materials
\end{abstract}

\section{Introduction}

$\mathrm{CdZnTe}(\mathrm{CZT})$ is the leading candidate material for large-volume room temperature X- and gamma-ray detectors. The energy resolution and uniformity

\footnotetext{
${ }^{*}$ Corresponding author

Email address: khkim1@korea.ac.kr (K. Kim )
} 
of CZT detectors have been considerably improved during the past 10 years, prompted by advances in crystal growth and material purification technologies. In addition, the available volumes of commercial detectors gradually increased from a few cubic millimeters to a few cubic centimeters [1].

The segregation coefficient $(\mathrm{k})$ is defined as the ratio of impurity (or elementals) concentration in the solid phase to that of in the liquid phase, and it is an important physical property of a material under study $[2,3]$. It affects the doping profile and the ingot uniformity of materials grown from the melt [4]. Generally accepted segregation coefficient of $\mathrm{Zn}$ in a CdTe host is 1.3 although its values can vary from from 1.05 to 1.6 depending on the growth method and the $\mathrm{Zn}$ content $[1,4,5,6,7,8,9]$.

The reported segregation coefficient of $\mathrm{Zn}$ is of higher unity so that $\mathrm{Zn}$ composition in CZT ingots decreases from the first-to-freeze part to the last-to-freeze part. The Zn non-uniformity on gamma-ray spectrometers would be a major obstacle to achieving statistically limited energy resolution in CZT detectors [10]. However, M. Azoulay et al. achieved a more uniform $\mathrm{Zn}$ distribution by using $\mathrm{Cd} / \mathrm{Zn}$ reservoir by a modified vertical gradient freeze method [6]. They used a $\mathrm{Cd} / \mathrm{Zn}$ reservoir to replenish $\mathrm{Zn}$ effectively to the melt through the vapor phase. With issues of non-uniformity results from $\mathrm{Zn}$, researchers have begun to pursue use of new materials such as $\mathrm{CdMnTe}(\mathrm{CMT})[11]$ which have high yields and allow use in a large volume single detector with the relatively small diameter ingot.

We have reported preliminary results on an anomalous Zn segregation in CdTe in a previous publication [12]. During the crystal growth process by the vertical Bridgman method, a CZT ingot remained at $700-800{ }^{\circ} \mathrm{C}$ for a week within the temperature gradient field of $10^{\circ} \mathrm{C} / \mathrm{cm}$ owing to the moving system's failure. For 
this ingot, we observed an unusual $\mathrm{Zn}$ distribution where the segregation behavior of $\mathrm{Zn}$ in CdTe looked like to be a less than 1, as shown in Fig. 1(a). This indicated that segregation of certain elements might be resolved by diffusion within the solid phase. Based on this observation, we tried to overcome the $\mathrm{Zn}$ segregation in CdTe by using in-situ and post-growth temperature gradient annealing (TGA).

\section{Experiment}

CZT detectors were grown by the Bridgman method from a melt mixture of $\mathrm{CdTe}(6 \mathrm{~N}), \mathrm{ZnTe}(6 \mathrm{~N})$, and 2-5 atomic percent of excess Te and 3-10 ppm of indium. The resistivity of these detectors was $0.8-5 \times 10^{10} \Omega \mathrm{cm}$ of resistivity, and their electron mobility-lifetime product was $0.9-5 \times 10^{-3} \mathrm{~cm}^{2} / \mathrm{V}$. A typical growth rate and an interface temperature gradient were $6 \mathrm{~mm} /$ day and $10-15^{\circ} \mathrm{C} / \mathrm{cm}$, respectively. During the cooling process, we intentionally applied in-situ TGA on CZT ingots in order to reproduce Zn diffusion within the solid phase. The in-situ TGA condition was $850^{\circ} \mathrm{C}$ for $32 \mathrm{~h}$ with the temperature gradient of $10^{\circ} \mathrm{C} / \mathrm{cm}$.

The "as-grown" ingots were sliced parallel to their growth direction and then finished by fine mechanical polishing to avoid potential stoichiometric changes that may occur after chemical etching. The typical CZT slabs were 1-in. wide, 34 in. long, and 3-mm thick. The Zn composition in CZT ingots was measured by using electron probe micro-analysis(EPMA). The measurements by EPMA cannot provide an accurate $\mathrm{Zn}$ composition such as ppm level reading but their accuracy is good enough to provide a Zn profile along the CZT slab.

To demonstrate that the thermo-migration of $\mathrm{Zn}$ is a common feature of CZT materials, we repeated similar post-growth annealing experiments by using smaller CZT samples $\left(5 \times 5 \times 2 \mathrm{~mm}^{3}\right)$ cut from the conventionally grown CZT wafers un- 
der $\mathrm{Cd}$ and Te overpressure with a temperature gradient.

We performed qualitative stoichiometric analysis of the samples by using microX-ray fluorescence ( $\mu$-XRF) available at BNL's National Synchrotron Light Source (X-27A). This allowed for a fast and non-destructive mapping of large sample areas in fine steps. The $\mu$-XRF instrument could trace $1 \mathrm{ppm}$ elemental compositions at a spot. We used $100-\mu \mathrm{m}$ or $500-\mu \mathrm{m}$ steps depending on the sample's scanning area. The quantitative changes in stoichiometry were also estimated by photoluminescence (PL) measurements at $4 \mathrm{~K}$ [13].

For the pulse height measurement at room temperature, the planar CZT detector was installed in a holder and the cathode side of the detector was irradiated. The signals from the positively biased anode were measured by using a capacitively-coupled eV Products 550 preamplifier. The data acquisition system included a spectroscopic shaping amplifier and a multi-channel analyzer (MCA).

\section{Results and Discussion}

Fig. 1 (b) shows the $\mu$-XRF maps for the CZT slabs cut from the ingots to which the TGA were applied during the crystal-cooling processes. The CZT slabs were mechanically polished only during the final step by using the $0.9-\mu \mathrm{m}-$ alumina powder. The Zn profiles in CZT slabs, to which the TGA were applied, were fairly uniform, as shown Fig. 1(b). In general, this is not a common $\mathrm{Zn}$ behavior for $\mathrm{CdTe}$, and it indicates thermo-migration/diffusion of $\mathrm{Zn}$ within in the solid phase.

The $\mathrm{Zn}$ distribution using a classical segregation law for the directional freezing can be evaluated by the following equation:

$$
C_{s}=C_{0} k(1-g)^{k-1}
$$


where $\mathrm{C}_{0}$ is the initial concentration and $g$ is the solidified fraction. In general, $\mathrm{Zn}$ segregates with a coefficient of 1.3 . In this case, $\mathrm{Zn}$ composition along the growth direction follows the classical segregation law as shown in Fig. 2 [9]. Open and closed circles in Fig. 2 represent the $\mathrm{Zn}$ composition obtained from the EPMA measurement for the TGA applied CZT slabs. As shown in the figure, the theoretical curve and the experimental data do not match in the segregation behaviour. The segregation coefficient of two TGA applied CZT slabs which were obtained by fitting EPMA data to classical segregation law were 0.61 and 1.01 for the slab 1 (TGA for $72 \mathrm{~h}$ at $750{ }^{\circ} \mathrm{C}$ ) and the slab 2 (TGA for $32 \mathrm{~h}$ at $850{ }^{\circ} \mathrm{C}$ ), respectively.

Fig. 3(a) shows a Zn profile measured for "as-grown" 1-inch-thick CZT wafers sliced perpendicularly to the growth direction. Since the Zn composition was uniform throughout the entire wafer, thus we discontinued with the $\mu$-XRF measurements during the measurement process. Some CZT samples were sliced in the wafers with dimensions of $5 \times 5 \mathrm{~mm}^{2}$ and were annealed under Cd overpressure at $700 / 600{ }^{\circ} \mathrm{C}(\mathrm{CdZnTe} / \mathrm{Cd})$ for $72 \mathrm{~h}$, with a temperature gradient of $20^{\circ} \mathrm{C} / \mathrm{cm}$. The annealed CZT samples were mechanically polished to remove $\mathrm{Cd}$ contaminated layers $(500-\mu \mathrm{m})$ prior to starting the $\mu$-XRF measurements. By contrast, the $\mathrm{Zn}$ profiles of the annealed sample exhibited prominent changes that correlated with the temperature gradients vs. thermo-migration of $\mathrm{Zn}$, even in a relatively small area $\left(1 \times 2.5 \mathrm{~mm}^{2}\right)$ as shown in Fig. $3(\mathrm{~b})$. We noted the same tendency in a CZT slab cooled in presence of a temperature gradient. A similar pattern was confirmed for the $\mathrm{CZT}$ sample annealed under Te overpressure at $700 / 800{ }^{\circ} \mathrm{C}(\mathrm{CdZnTe} / \mathrm{Te})$ for $72 \mathrm{~h}$, with the temperature gradient of $40^{\circ} \mathrm{C} / \mathrm{cm}$, as shown in Fig. 3(c). In Fig. 3(b), the temperature gradient was applied to the sample in the horizontal direc- 
tion, while in Fig. 3(c) it was applied in the perpendicular direction. We note that the $\mathrm{Zn}$ variation perpendicular to the direction of temperature gradient was only minor. These TGA experiments, performed with "as-grown" ingots and small individual samples, led us to conclude that $\mathrm{Zn}$ concentration becomes high along the positive temperature gradient field. We again state that in the control sample annealing experiments performed at isothermal conditions, we did not observe any significant differences for $\mathrm{Zn}$ under either Cd- or Te-overpressure.

We quantitatively analyzed Zn migration via PL measurements. Fig. 4 shows the PL spectrum for an "as-grown" CZT sample. We observed a donor-bound $\left(\mathrm{D}^{\circ} \mathrm{X}\right)$ and an acceptor-bound exciton $\left(\mathrm{A}^{\circ} \mathrm{X}\right)$ around 1.659- and 1.648-eV, respectively. In addition, strong intensity of donor-acceptor pair (DAP) recombination band was apparent at $1.595 \mathrm{eV}$ and disappeared after $\mathrm{Cd}$ annealing. The A-center peak, reflecting the complex of Cd vacancies and compensating dopant, was visible at $1.453 \mathrm{eV}$ in "as-grown" samples but it also disappeared after Cd annealing. In case of $\mathrm{Cd}$ annealing, the $\mathrm{Cd}$ vacancies filled by the $\mathrm{Cd}$ atoms under $\mathrm{Cd}$ overpressure and the reduction of Cd vacancies resulted in the disappearance of the DAP and the A-center, $\left(\mathrm{V}_{\mathrm{Cd}}-\mathrm{In}_{\mathrm{Cd}}\right)^{-}$. We calculated $\mathrm{Zn}$ composition from the exciton peak - before annealing it was about $9.73 \%$, but after annealing it decreased to $7.42 \%$ after annealing. Zn composition was calculated by using the following relations [13]:

$$
E_{g}(x, 4 K)=1.606+0.520 x+0.254 x^{2},
$$

where $\mathrm{E}_{\mathrm{g}}$ is the bandgap at $4 \mathrm{~K}$ and $x$ is the $\mathrm{Zn}$ composition.

Considering all the experimental conditions, the only factor causing Zn migration in the CZT ingots/samples [14] was the temperature gradient. Previously, the rate of diffusion of zinc in CdTe at a negligible concentrations gradient has been 
determined to be $10^{-9} \sim 10^{-10} \mathrm{~cm}^{2} / \mathrm{s}$ in the range of 800 to $900{ }^{\circ} \mathrm{C}[15,16]$. This compares favorably with the value for the self-diffusion of $\mathrm{Cd}$ in $\mathrm{CdTe}$. The diffusion length can be estimated using following equation:

$$
L_{D}=\sqrt{D t}
$$

where $\mathrm{D}$ is diffusivity $\left(\mathrm{cm}^{2} / \mathrm{s}\right)$ and $\mathrm{t}$ is time $(\mathrm{s})$. The uniform $\mathrm{Zn}$ distribution cannot be explained only by the self-diffusion process considering the length of CZT ingots is about $7 \mathrm{~cm}$. The diffusion length of $\mathrm{Zn}$ is $10^{-2}-\mathrm{cm}$ order in case of the $10^{-9}\left(\mathrm{~cm}^{2} / \mathrm{s}\right)$ diffusivity. To satisfy our in-situ annealing condition, the diffusivity should be in the order of $10^{-5}\left(\mathrm{~cm}^{2} / \mathrm{s}\right)$.

Aslam et al. reported that the addition of $\mathrm{Cd}$ and $\mathrm{Te}$ to the diffusion source did not affect the diffusivity of $\mathrm{Zn}$ at any temperature. Studies of $\mathrm{Zn}$ self-diffusion in $\mathrm{ZnTe}$ with ${ }^{65} \mathrm{Zn}$ elucidated that self-diffusion is controlled by native defects concentrations that depend only on thermal disorder, rather than on deviations from stoichiometry $[15,17]$. In the post-growth TGA experiment [12], thermomigration velocity did not show any $\mathrm{Cd}$ or Te pressure dependence. However, the diffusion mechanism of $\mathrm{Zn}$ in in-situ and post-growth TGA looked completely different in point view of thermo-migration velocity. In case of in-situ TGA, the fast diffusion dominates with diffusivity in the order of $10^{-5}\left(\mathrm{~cm}^{2} / \mathrm{s}\right)$. In general, for fast diffusion involves defects in in both interstitial and substitutional sites [16]. In in-situ TGA, temperature gradient on the CZT ingots yield a concentration gradient of $\mathrm{Cd}$ vacancies and provides a pathway for $\mathrm{Zn}$ migration toward high concentrations of $\mathrm{Cd}$ vacancies for achieving chemical equilibrium. We need further investigation is required to clarify this behavior.

The Two TGA, namely in-situ TGA and post growth TGA, give a notable difference in resistivity after the annealing process. The bulk resistivity of CZT 
samples cut from in-situ TGA ingots was found to be $0.5-1 \times 10^{10} \Omega \cdot \mathrm{cm}$, which is similar in value obtained from the normally cooled CZT ingots. However, the resistivity decreased to $10^{3}-10^{6} \Omega \cdot \mathrm{cm}$ after the post-growth TGA of the whole ingots or wafers regardless Te and/or Cd overpressure.

Figure 5 shows the pulse height spectrum of ${ }^{241} \mathrm{Am}$ taken with CZT detector which came from in-situ TGA applied CZT ingot. Full width half maximum (FWHM) of $59.5 \mathrm{keV}$ is $10.06 \%$ and that is similar value to other CZT detector which did not going through the TGA.

\section{Conclusion}

In summary, we observed Zn migration in CZT ingots and in prepared small samples annealed under a temperature gradient. We demonstrated that $\mathrm{Zn}$ composition in both CZT ingots and wafers can be adjusted by using the proper thermal conditions as with the temperature and its gradient, thereby controlling the speed of $\mathrm{Zn}$ migration and the distribution of $\mathrm{Zn}$ in the material. The mechanism behind the fast diffusion with a diffusivity in order of $10^{-5}\left(\mathrm{~cm}^{2} / \mathrm{s}\right)$ order is not clear but it might be related to the defects in both interstitial and substitutional sites.

This approach described here can be used for fabrication of large-volume CZT crystals with uniform distribution of $\mathrm{Zn}$ that are required for highly effective largearea X-and gamma-ray detectors and for generating large-area CZT substrates for growing $\mathrm{HgCdTe}$ epilayers for infrared detectors. Besides for "as-grown" CZT ingots and wafers, our approach may also have impact on methods for modifying the zinc composition in and around spatially extended defects, such as high-angle grain boundaries, twins and possiblely cellular networks. This new understanding is likely to have significant implications for manufacture of II-VI electronic 
devices.

\section{Acknowledgement}

This work was supported by the National Research Foundation of Korea (NRF) grant funded by the Korea government (MSIP) (NRF-2015M2B2A9032788 and NRF-2015M2A2A4A01045094) and the U.S. Department of Energy Office of Defense Nuclear Nonproliferation Research and Development, DNN R\&D.

\section{References}

[1] R. B. James, T. E. Schlesinger, J. Lund, and M. Schieber, Semiconductors and Semimetals Vol. 43: Semiconductors for Room Temperature Nuclear Detector Applications, (Academic Press, NY, 1995).

[2] S. Terterian, M. Chu, and D. Ting, J. Electron. Mater. 33, 640 (2004).

[3] M. Schieber, T. E. Schlesinger, R. B. James, H. Hermon, H. Yoon, and M. Goorsky, J. Cryst. Growth 237-239, 2082 (2002).

[4] P. Capper, J. E. Harris, E. S. O'Keefe, C. L. Jones, and I. Gale, Adv. Mater. Opt. Electron. 5 (2), 101 (1995).

[5] C. Szeles, S. E. Cameron, S. A. Soldner, J. Ndap, and M. D. Reed, J. Electron. Mater. 33, 742 (2004).

[6] M. Azoulay, S. Rotter, G. Gafni, R. Tenne, and M. Roth, J. Cryst. Growth 117, 276 (1992).

[7] P. Fougeres, L. Chibani, M. Hageali, J. M. Koebel, G. Hennard, A. Zumbiehl, P. Siffert, and M. Benkaddour, J. Cryst. Growth 197, 641 (1999). 
[8] Y. Tao, and S. Kou, J. Cryst. Growth 181, 301 (1997).

[9] A. Zappettini, M. Zha, L. Marchini, and D. Calestani, Cryst. Eng. Comm. 14, 5992 (2012).

[10] J. E. Toney, T. E. Schlesinger, and R. B. James, IEEE Trans. Nucl. Sci. 45(1), 105 (1998).

[11] K. H. Kim, Chansun Park, Pilsu Kim, Shinhaeng Cho et al, J. Korean. Phys. Soc. 66 (11), 1761 (2015).

[12] K. H. Kim, A. E. Bolotnikov, G. S. Camarda et al, IEEE Trans. Nucl. Sci. $\mathbf{5 9}(4), 1510$ (2012).

[13] J. Franc, P. Hlidek, P. Moravec, E. Belas, P. Hoschl, L. Turjanska, and R. Varghova, Semicond. Sci. Technol 15, 561 (2000).

[14] A. Zappettini, L. Marchini, M. Zha, G. Piacentini, N. Zambelli, G. Benassi, and D. Calestani, Cryst. Eng. Comm. 15, 2227 (2013).

[15] N. Aslam, E. D. Jones, T. C. Q. Noakers, J. B. Mullin, and A. F. W. Willoughby, J. Cryst. Growth 117, 249 (1992).

[16] E. D. Jones, J. C. Clark, J. B. Mullin, and A. W. Brinkman, J. Cryst, Growth 138, 274 (1994).

[17] R. A. Raynolds and D. A. Stevenson, J. Phys. Chem. Solids 30, 139 (1969). 


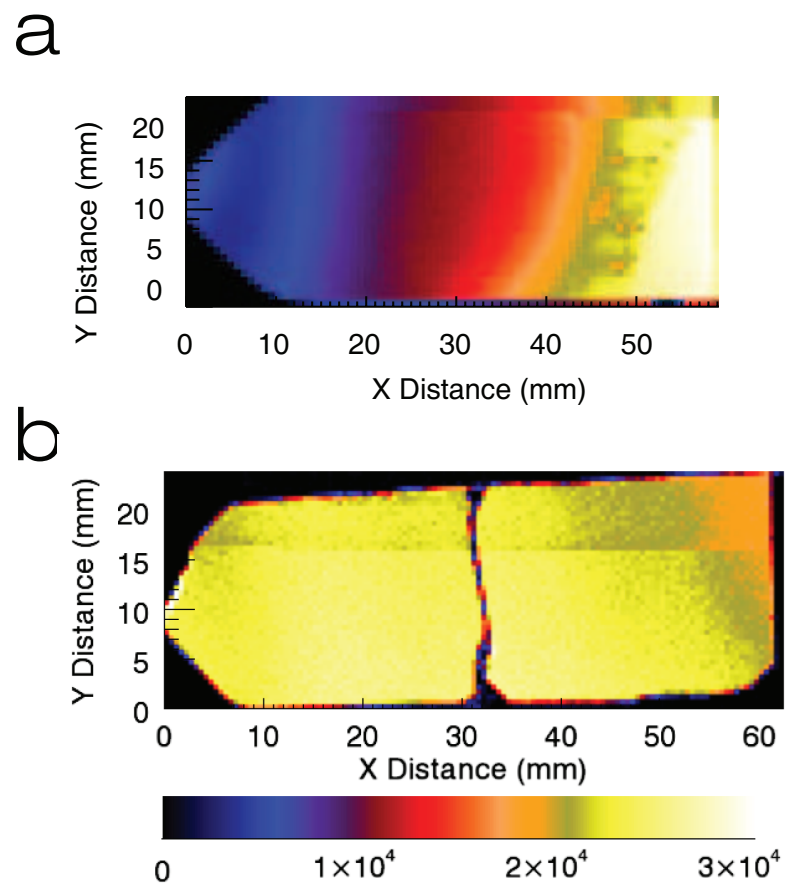

Figure 1: $\mu$-XRF images of CZT slabs $\left(22 \times 60 \mathrm{~mm}^{2}\right)$ exhibiting abnormal and uniform Zn distributions after in-situ TGA applied for (a) $72 \mathrm{~h}$ at $750{ }^{\circ} \mathrm{C}$ and (b) $32 \mathrm{~h}$ at $850{ }^{\circ} \mathrm{C}$ with the temperature gradient of $10^{\circ} \mathrm{C} / \mathrm{cm}$. The CZT slab annealed $72 \mathrm{~h}$ at $750{ }^{\circ} \mathrm{C}$ exhibited an abnormally low $\mathrm{Zn}$ concentration in the first-to-freeze parts and high $\mathrm{Zn}$ concentrations in the last-to-freeze parts. However, the slab that was annealed in-situ for $32 \mathrm{~h} 850{ }^{\circ} \mathrm{C}$ exhibited relatively uniform distribution of $\mathrm{Zn}$. The color bar on the bottom indicates the counts of $12 \mathrm{keV} \mathrm{Zn} \mathrm{K}_{\alpha}$ signals. The streak that appears in the image is an artifact, arising from beam injection at the National Synchrotron Light Source(NSLS). 


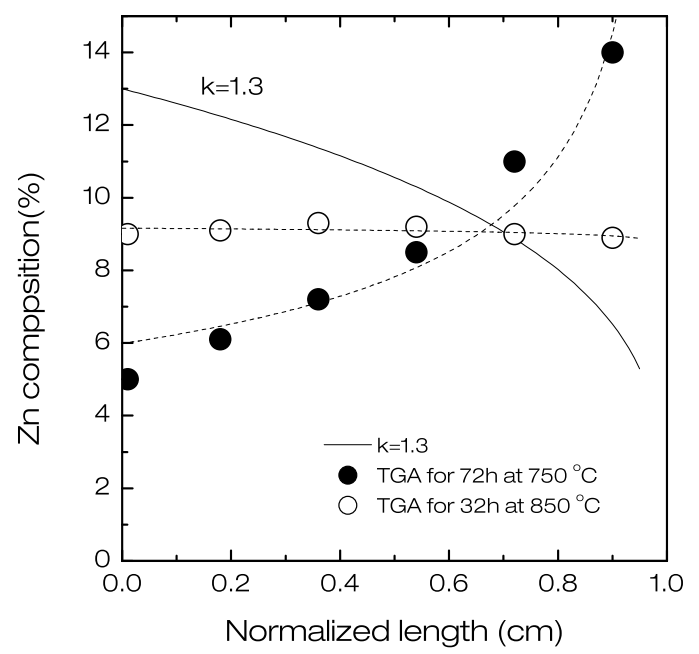

Figure 2: The Zn distribution along the growth direction after in-situ TGA applied for $72 \mathrm{~h}$ at 750 ${ }^{\circ} \mathrm{C}$ (closed circle) and for $32 \mathrm{~h}$ at $850{ }^{\circ} \mathrm{C}$ (open circle) with the temperature gradient of $10{ }^{\circ} \mathrm{C} / \mathrm{cm}$. The solid line indicates classical $\mathrm{Zn}$ distribution with segregation coefficient $(\mathrm{k})$ of 1.3. 


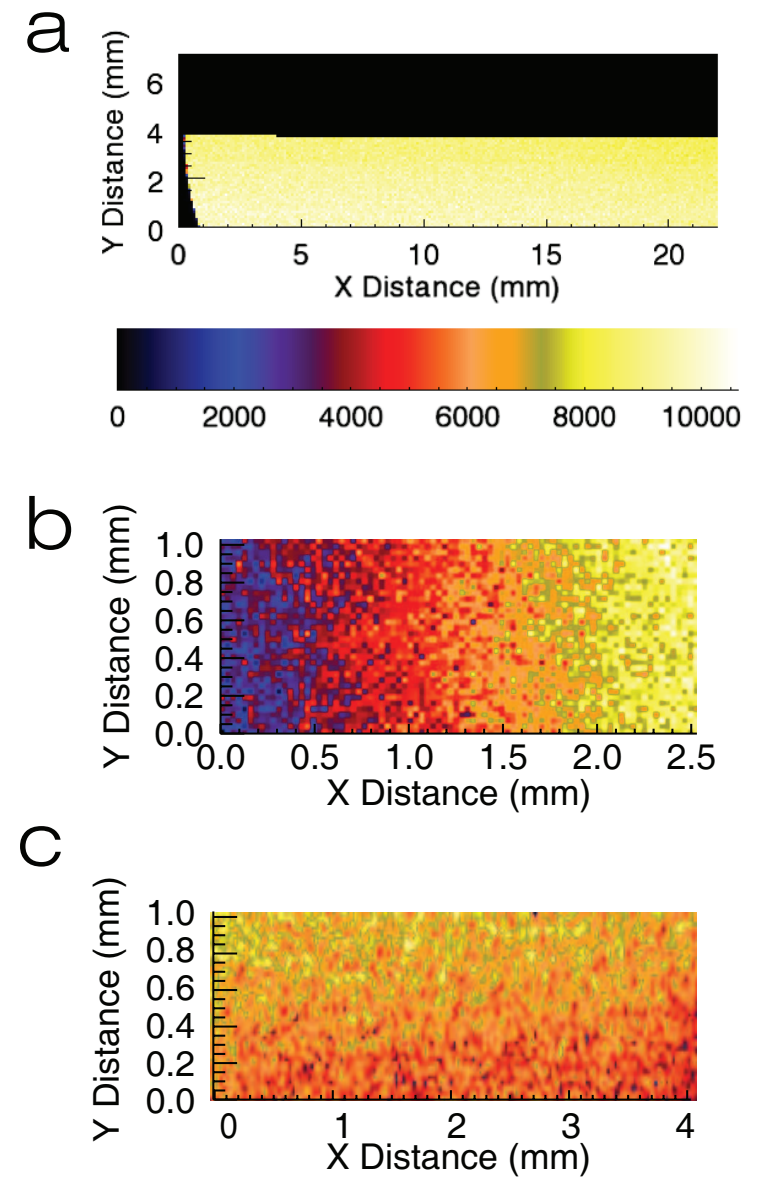

Figure 3: Distribution of $\mathrm{Zn}$ in (a) 1-in.-diameter wafer and (b) CZT samples that were temperature-gradient $(\Delta \mathrm{T})$ annealed at $700 / 600{ }^{\circ} \mathrm{C}(\mathrm{CdZnTe} / \mathrm{Cd})$ with $\Delta \mathrm{T}=20^{\circ} \mathrm{C} / \mathrm{cm}$ for 72 $\mathrm{h}$ under $\mathrm{Cd}$ overpressure and (c) samples that were annealed at $700 / 800^{\circ} \mathrm{C}(\mathrm{CdZnTe} / \mathrm{Te})$ with $\Delta \mathrm{T}$ $=40^{\circ} \mathrm{C} / \mathrm{cm}$ for $72 \mathrm{~h}$ under Te overpressure. The temperature gradients were applied to the horizontal in (b) and vertical in (c) each image. In both images, the $\mathrm{Zn}$ signal increased in the direction of the positive temperature gradient. 


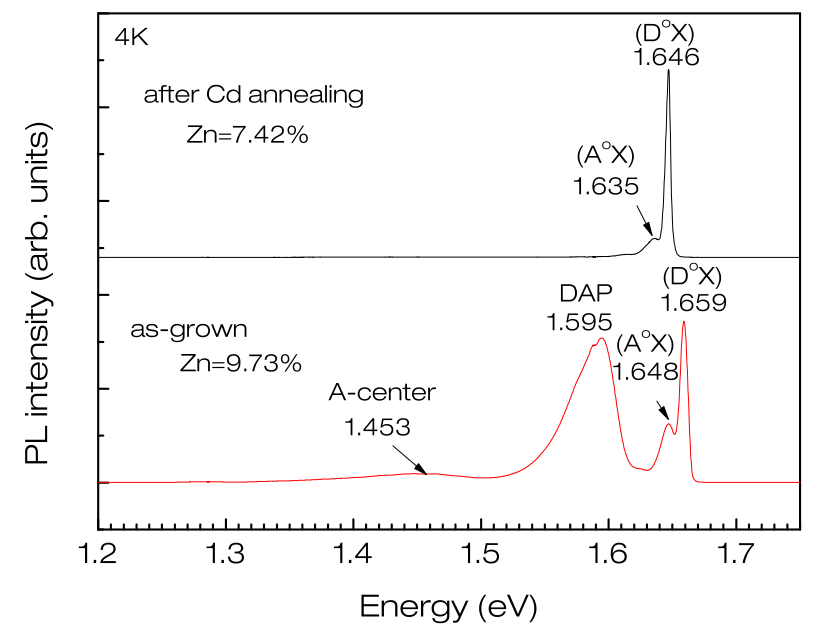

Figure 4: PL spectra of (a) the "as-grown" CZT sample and (b) the CZT sample annealed at $700 / 600{ }^{\circ} \mathrm{C}(\mathrm{CdZnTe} / \mathrm{Cd})$ for $72 \mathrm{~h}$ under $\mathrm{Cd}$ overpressure with TGA of $40{ }^{\circ} \mathrm{C} / \mathrm{cm}$. Red-shift of exciton peak can be observed clearly owing to the migration of $\mathrm{Zn}$. 


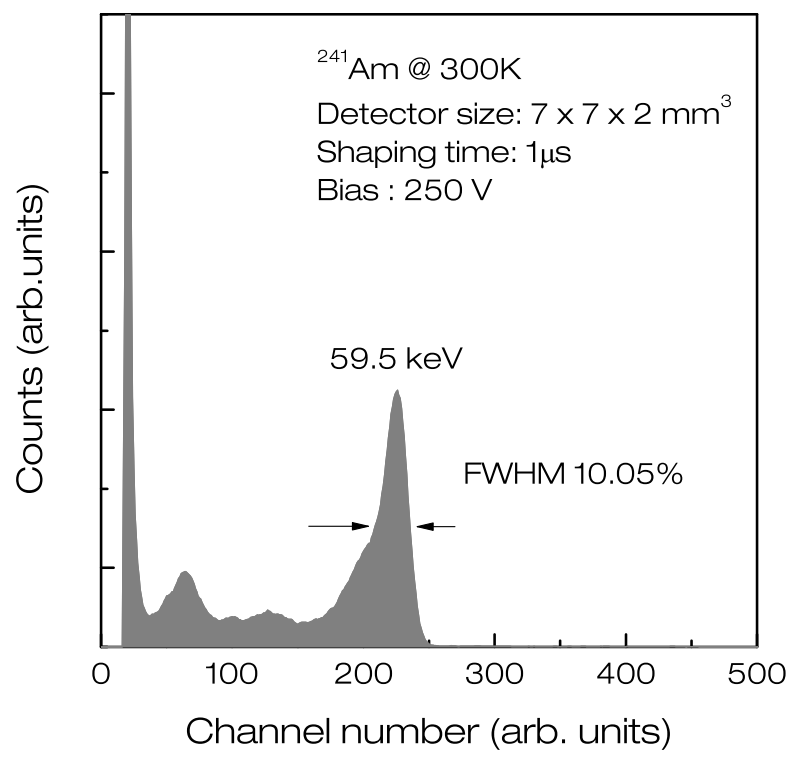

Figure 5: Pulse height spectrum of ${ }^{241} \mathrm{Am}$ obtained by using a planar CZT detector at $300 \mathrm{~K}$ with $250 \mathrm{~V}$. The CZT detector fabricated using in-situ TGA applied CZT ingot for $32 \mathrm{~h}$ at $850{ }^{\circ} \mathrm{C}$. The shaping time was $1 \mu \mathrm{s}$. The 59.5 peak is asymmetric due to the hole tailing. 